\title{
HOMENS RESPONSÁVEIS POR CRIANÇAS EM AMBITO FAMILIAR: heroísmo ou
} responsabilidade?

\author{
MEN RESPONSIBLE FOR FAMILY CHILDREN: heroism or responsibility?
}

\author{
Valdelice Cruz da Silva Souza ${ }^{1}$ \\ Josiane Peres Gonçalves ${ }^{2}$
}

\section{http://dx.doi.org/10.52641/cadcaj.v7i1.567}

\begin{abstract}
RESUMO: Objetivou-se com o estudo investigar as vivências de homens responsáveis por crianças na família, destacando quais os desafios vivenciados por eles ao desempenharem funções que são atribuídas socialmente às mulheres. A abordagem teórica baseia-se nos estudos de gênero e em legislações relativas à guarda dos filhos em decorrência da separação dos pais, especialmente a guarda compartilhada. Participaram da pesquisa quatro homens responsáveis por crianças e duas mediadoras da vara de família. Os resultados evidenciam que os homens não sofrem discriminação e são vistos como heróis em âmbito social, diferente do que ocorre com professores homens em âmbito escolar.
\end{abstract}

Palavras-chaves: Homens. Gênero. Guarda compartilhada.

ABSTRACT: Objective, how I study to investigate the experiences of homens responsible for children in the family, highlighting the challenges experienced by the year or performing functions that are socially attributed to women. A theoretical approach based on gender studies and legislation relating to keeping two filhos in decorum of the separation of two countries, especially to shared custody. Participate in the investigation of four homens responsible for children and two mediators of the family rod. The results show that homens do not suffer from discrimination and are seen as heroes in the social sphere, different from what happens with home teachers in the school sphere.

Keywords: Men. Genre. Shared guard.

\section{INTRODUÇÃO}

Diante de resultados obtidos em pesquisas anteriores realizadas pelo Grupo de Estudo e Pesquisa em Desenvolvimento, Gênero e Educação (GEPDGE) sobre o trabalho desenvolvido por professores homens com criança em instituições escolares, em que se evidenciaram preconceitos relativos ao contato do profissional do sexo masculino com crianças de 0 a 6 anos, surgiu o interesse de analisar as experiências de homens que cuidam de crianças na família.

\footnotetext{
${ }^{1}$ Mestre em Educação pelo Programa de Pós-graduação em Educação da Universidade Federal de Mato Grosso do Sul. Professora da Rede Municipal de Ensino de Sidrolândia-MS. Orcid: https://orcid.org/0000-0002-39875256. E-mail: valczsouza@gmail.com.

2 Professora do Programa de Pós-graduação em Educação da Universidade Federal de Mato Grosso do Sul. Orcid: https://orcid.org/0000-0002-7005-849X. E-mail: josianeperes7@,hotmail.com.
} 
Apesar de os homens historicamente terem se privado de cuidar de pessoas, especialmente de crianças, e nas instituições educativas o preconceito parece ser ainda maior, na sociedade tem ocorrido alguns avanços no sentido de incentivar que os homens participem do processo de educar e cuidar dos filhos, por ser entendido como um direito da criança. No Brasil foi sancionada a Lei $\mathrm{n}^{\circ}$ 13.257/2016, de 08 de março de 2016, sobre a ampliação da licença paternidade, de 5 para 20 dias, possibilitando assim que os homens possam ficar mais tempo com os filhos logo após o nascimento. A referida lei é válida para servidores públicos e para empresas que fazem parte do Programa Empresa Cidadã (BRASIL, 2016).

Outra legislação importante, que garante à criança o direito de continuar sendo cuidada e educada pela mãe e pelo pai após a separação do casal, é a Lei no 13.058/2014³ , de 22 de dezembro de 2014, sobre a guarda compartilhada, que em no Art. $2^{\circ}, \rrbracket 2^{\circ}$ prevê: "Na guarda compartilhada, o tempo de convívio com os filhos deve ser dividido de forma equilibrada com a mãe e com o pai, sempre tendo em vista as condições fáticas e os interesses dos filhos” (BRASIL, 2014).

Anteriormente a essa lei, o que predominava era a guarda unilateral, em que geralmente a criança ficava com a mãe. Nesse sentido, Fehlauer (2009) salienta que uns dos motivos que levam os indivíduos, tanto homens quanto mulheres, a se responsabilizar pelos cuidados de uma criança é a guarda unilateral e compartilhada, que ocorrem geralmente após a separação do casal. Assim, a guarda unilateral é “[...] aquela concedida a um só dos genitores ou a alguém que o substitua" (p. 40), considerando a pessoa que oferece maiores cuidados as crianças. "A guarda é concedida ao genitor que possui melhores condições de atribuí-la, levando em consideração: o ambiente familiar, as condições financeiras, as condições de moradia, a possibilidade de assistência, saúde, educação entre outras" (FEHLAUER, 2009, p. 41). Por outro lado, a autora salienta que "Compreende-se por guarda compartilhada, o modelo de guarda fixada para ambos os genitores. Ainda que não vivam sob o mesmo teto, os genitores possuem responsabilidades conjuntas para com os filhos" (p. 41). Deste modo, acredita-se que nessas condições, a função e o compromisso dos pais em relação aos filhos não foram alterados após o término do relacionamento.

Fehlauer (2009, p. 43) ressalta que as transformações ocorridas na sociedade após a ingressão da mulher no mercado de trabalho contribuíram para que quebrasse o protótipo de que os cuidados dos filhos e afazeres domésticos estão somente incumbidos às mulheres, tornando-a como colaboradora nas finanças do lar. Assim, os homens passaram a ser mais participativos nas tarefas familiares, porém após o término do casamento, as mulheres continuaram a serem vistas

\footnotetext{
${ }^{3}$ A lei 13.058/2014 alterou a lei 10.406/2010, que por sua vez alterou a lei 11.698/2008 a qual foi a primeira a fazer modificações no código civil.
} 
como as principais responsáveis pelos filhos e os homens se responsabilizavam essencialmente pelas necessidades financeiras.

O conceito social de que a genitora deveria ser a responsável pela guarda dos filhos, como figura indispensável na criação da prole, transferiu-se para o conceito jurídico e as decisões eram proferidas normalmente em favor da mãe. O pai era apenas o responsável pelo pagamento da pensão alimentícia e as visitas aos fins de semana (FEHLAUER, 2009, p. 44).

Observa-se que as mulheres eram encarregadas das obrigações com os filhos e os pais eram os mantenedores, mas a guarda compartilhada veio intervir e propor igualdade de deveres e direitos entre os pais. Nesse cenário, o compartilhamento da guarda representa um tipo de chamamento aos pais que vivem separados, mas que devem exercer conjuntamente as responsabilidades para com os filhos, mediante a valorização da convivência entre ambos e co-participação igualitária no processo educativo dos filhos (FEHLAUER, 2009).

Compreende-se que esse procedimento possibilita a atuação dos homens aos cuidados dos filhos, resultando na paternidade participativa, entendida como "[...] aquela que subentende o cuidado e o envolvimento constante no cotidiano dos filhos - nos domínios da alimentação, higiene, lazer e educação" conforme Sutter e Maluschke (2008, p. 75). Nesse sentido, o que justifica o fato de os homens estarem mais envolvidos com as funções vistas socialmente como femininas é o aumento de famílias monoparentais, que na maioria das vezes são lideradas por mulheres, diminuindo assim o grau de importância da presença do homem no âmbito familiar.

A nova concepção familiar está amparada pela Constituição de 1988, que no Art. 226, parágrafo $4^{\circ}$ enfatiza: "Entende-se também, como entidade familiar a comunidade formada por qualquer dos pais e seus descendentes” (BRASIL, 1988). Essa medida foi necessária, conforme Dias (2009), para que o novo conceito de família pudesse ser reconhecido legalmente, já que faz parte da realidade atual.

O enlaçamento dos vínculos familiares constituídos por um dos genitores com seus filhos, no âmbito da especial proteção do Estado, atende uma realidade que precisa ser arrostada. Tais entidades familiares receberam em sede doutrinária o nome de família monoparental, como forma de ressaltar a presença de somente um dos pais na titularidade do vínculo familiar (DIAS, 2009, p. 48).

Os motivos pelos quais se fez notório o reconhecimento e crescimento da família monoparental estão relacionados à decadência do papel do homem respeitável, do chefe de família, um modo de vida patriarcal e também pela ingressão da mulher no mercado de trabalho.

Com o declínio do patriarcalismo e a inserção da mulher no mercado de trabalho, as famílias constituídas por um dos pais e a sua prole passaram a ter maior 
visibilidade. Seu expressivo número, com maciça predominância feminina, é uma forte oposição ao modelo dominante bipolaridade (DIAS, 2009, p. 197).

De acordo com Bustamante e Trad (2005), a busca do homem em se adaptar a essa nova realidade é denominada como o conceito do "novo pai", em que ele se interessa pelas obrigações com os cuidados dos filhos. Por outro lado, ainda existe na sociedade o conceito de que o homem não nasceu para realizar certas atividades com crianças pequenas, principalmente quando se trata do contato físico "[...] os cuidados que envolvem manipulação do corpo são considerados 'negócios de mulher', algo que a mulher faz melhor, como parte de seus instintos e porque desde cedo se preparou para isso" (p. 1.870). É importante destacar que durante toda a criação os papéis de gênero são definidos pela sociedade, desde modo, percebe-se a falta de preparo dos homens que não foram ensinados a cuidar de crianças.

Conforme Correia (2010, p. 133), o número de pais solteiros é extremamente reduzido “[...] as famílias de pai-só com filhos menores, solteiros e dependentes constituem uma franja muito estreita do quadro de famílias monoparentais e uma ínfima parte da composição das famílias na nossa sociedade", o que leva a concepção de que ainda é muito forte a interpretação de que, cuidados infantis estão inteiramente ligados à figura feminina e que pouco se sabe sobre tais situações em que o pai é o responsável.

No que se refere ao âmbito escolar, o cenário não muda, os profissionais do sexo masculino tendem a sofrer preconceitos ao trabalharem com crianças pequenas. Na perspectiva de Rabelo (2013, p. 911), “[...] os professores do sexo masculino atuantes nas séries iniciais do ensino fundamental sentem fortemente as questões de gênero. O que gera maior aflição a esses docentes, são as experiências de discriminação que vivenciaram ou presenciaram". Ou seja, o docente enfrenta especulações a respeito do seu trabalho devido ao gênero a qual pertence. Nota-se uma forte ideologia de que o homem não possui habilidades para exercer tal profissão "[...] ele é homem e por isso não tem as características femininas essenciais para ser um bom professor" (p. 911), isto é, o homem não dispõe de dons para cuidar de outro ser e a docência está estritamente voltada às mulheres.

Conforme Ramos (2011), geralmente o público participante na vida escolar dos filhos são as mães, reforçando ainda mais o pensamento de que quem cuida de criança é a mulher. "Os participantes de grupos de discussão de pais e parentes de crianças reprovaram a presença do homem executando ações relacionadas ao cuidado" (p. 105). Estudos realizados por Faria e Gonçalves (2016), Gonçalves e Faria (2016), Gonçalves e Oliveira (2016), Gonçalves, Dias e Souza (2017), Gonçalves, Souza e Reis (2017), Gonçalves e Oliveira (2017) Gonçalves, Ferreira e Capristo (2018), entre outros, corroboram com essas ideias de a comunidade escolar não aceita a 
possibilidade de professores homens cuidarem de crianças em instituições educativas. Deste modo, observa-se que de fato a sociedade discrimina atividades exercidas pelo sexo masculino com as crianças evidenciando representações sociais relativas às questões de gênero em âmbito escolar. Mas o que se entende por gênero e representações sociais?

De acordo com Scott (1998), o gênero é usado para distinguir os sexos no que se refere aos comportamentos e atitudes, uma vez que seu uso representa um elenco de posições teóricas e referências descritivas inerentes às relações entre os sexos. Também Vianna e Finco (2009, p. 269) descrevem que gênero remete "[...] à dinâmica de transformação social, aos significados que vão além dos corpos e do sexo biológico e que subsidiam noções, ideias e valores nas distintas áreas da organização social” Assim, é possível encontrar os gêneros nos "[...] símbolos culturalmente disponíveis sobre masculinidade e feminilidade".

Percebe-se que além da questão biológica a diferenciação entre os sexos relaciona-se com as ações dos indivíduos diante da sociedade, ou seja, como o homem ou a mulher devem agir, de modo que esse ato determine a qual sexo pertencem.

[...] gênero é uma maneira de se indicar as "construções sociais" - a criação inteiramente social da idéias sobre papéis próprios aos homens e ás mulheres. É uma maneira de se referir ás origens exclusivamente sociais das identidades subjetivas dos homens e das mulheres. O gênero é, segundo essa definição, uma categoria social imposta sobre um corpo sexuado (SCOTT, 1998, p. 7).

Com base nessas informações, é possível perceber a influência das representações sociais, sobre o comportamento entre os sexos, isto é, a maneira pela qual um determinado grupo pensa e organiza suas regras, normas, condutas, um modelo a ser seguido. Nesse contexto, Jodelett (2001, p. 5) analisa as representações sociais como:

[...] sistemas de interpretação, que regem nossa relação com o mundo e com os outros, orientando e organizando as condutas e as comunicações sociais. Igualmente intervêm em processos tão variados quanto a difusão e a assimilação dos conhecimentos, no desenvolvimento individual e coletivo, na definição das identidades pessoais e sociais, na expressão dos grupos e nas transformações sociais.

Entende-se, portanto que a questão de gênero se trata de uma construção social, dissipada pelas representações sociais, ou seja, a maneira de agir, considerado adequado pela maioria, e que se torna um padrão de vida a ser seguido. Assim, é possível afirmar que as representações que relacionam a educação e cuidado de crianças como sendo responsabilidade feminina também foram construídas socialmente e na atualidade os homens que são os principais responsáveis por crianças na sociedade devem vivenciar alguma forma de preconceito. 
Contudo, ao considerar que gênero é resultado de um processo de construção social, é possível afirmar que tudo o que foi construído, pode também ser desconstruído, a fim de que as relações humanas sejam mais igualitárias. "Esta desconstrução permite a abertura para estarmos cientes que a categoria 'gênero' é histórica e passa por constantes re-significações, que podem ser contestadas a todo momento" (BITENCOURT, 2013, p. 184-185). Ou seja, "[...] tudo que é construído, pode ser mudado. Essa é a boa notícia” (p. 185). Se historicamente as funções relativas ao cuidado de crianças foram atribuídas às mulheres, não significa que deverá ser sempre assim, visto que é possível descontruir essas representações, e contar com a presença masculina nas atividades inerentes aos cuidados infantis.

Diante do exposto, destaca-se que o presente estudo tem por objetivo investigar as vivências de homens que cuidam e educam crianças de 0 a 6 anos na família, destacando quais desafios, perspectivas ou preconceitos são vivenciados por esses homens ao desempenhar funções que são atribuídas às mulheres, estabelecendo relações com as atividades de cuidar e educar crianças exercidas por homens em âmbito familiar e escolar.

\section{METODOLOGIA}

A pesquisa de campo realizada se caracteriza como qualitativa, sendo realizada por meio de um roteiro de entrevistas semiestruturadas, que permite ao pesquisador obter informações que não estão devidamente precisas, visto que certos temas podem gerar constrangimentos aos entrevistados, fazendo que se reprimam e não expressem sua verdadeira opinião.

Entrevistas são fundamentais quando se precisa/deseja mapear práticas, crenças,
valores e sistemas classificatórios de universos sociais específicos, mais ou menos
bem delimitados, em que os conflitos e contradições não estejam claramente
explicitados. Nesse caso, se forem bem realizadas, elas permitirão ao pesquisador
fazer uma espécie de mergulho em profundidade, coletando indícios dos modos
como cada um daqueles sujeitos percebe e significa sua realidade e levantando
informações consistentes que lhe permitam descrever e compreender a lógica
que preside as relações que se estabelecem no interior daquele grupo, o que, em
geral, é mais difícil obter com outros instrumentos de coleta de dados (DUARTE
2004. p. 215).

Nessa perspectiva, Godoy (1995) salienta a relevância de o pesquisador tomar conhecimento do lugar em que o entrevistado vive e, dessa forma, a interpretação dos dados coletado se tornam mais objetivo. 
Os estudos denominados qualitativos têm como preocupação fundamental o estudo e análise do mundo empírico em se ambiente natural. Nessa abordagem valoriza-se o contato direto e prolongado do pesquisador com o ambiente e a situação que está sendo estudada [...] Para esses pesquisadores um fenômeno pode ser mais bem observado e compreendido no contexto em que ocorre e do qual é parte. Aqui o pesquisador deve aprender a usar sua própria pessoa como instrumento mais confiável de observação, seleção, análise e interpretação dos dados coletados (GODOY, 1995. p. 62).

Para a autora, essa abordagem não enfatiza os números e a quantidade nos resultados "Rejeitando a expressão quantitativa, numérica, os dados coletados aparecem sob a forma de transcrições de entrevistas, anotações de campo, fotografias, videoteipes, desenhos e vários tipos de documentos" (p. 62), mas sim, a autenticidade da visão do mundo em que o sujeito está submetido, a partir de seu habitat natural "Os pesquisadores qualitativos tentam compreender os fenômenos que estão sendo estudados a partir da perspectiva dos participantes” (p. 63). Desse modo, é possível captar o que não foi dito explicitamente "Considerando todos os pontos de vista como importantes, este tipo de pesquisa 'ilumina', esclarece o dinamismo interno das situações, frequentemente invisível para observadores externos" (p. 63), possibilitando alcançar o objetivo dos estudos.

Para a realização da pesquisa, foram entrevistados dois avós, os quais se tornaram os responsáveis pelos netos devido a assuntos familiares, dois pais que da mesma forma eram responsáveis pelos cuidados dos filhos e duas mediadoras atuantes na vara familiar, sendo os participantes domiciliados na capital e em uma cidade do interior do Estado de Mato Grosso do Sul.

Para melhor compreensão sobre a guarda compartilhada (um dos aspectos para analisar a vivência de homens com crianças pequenas), optou-se em pesquisar mediadoras da vara familiar, por não ter sido encontrado homens que cuidam de crianças por terem a guarda compartilhada, evidenciando assim que a lei vigente sobre a guarda dos filhos não está sendo efetiva. No momento, cabe ressaltar sobre as competências de um mediador, que nos termos judiciais atuam como:

[...] auxiliar de da justiça (art. $7^{\circ}$ da Lei n. 0.099/1995) e exerce um papel relevante no desenvolvimento da cidadania, pois não apenas facilita o entendimento entre os cidadãos na busca da melhor solução para seus conflitos, mas também os ajuda na condução dos processos, no aspecto técnico, obviamente mantendo a imparcialidade que lhe é própria, mas dando objetividade ao processo, caso não haja acordo (TJMS, 2015, p. 247).

Nesse sentido, Takassi e Bertoncini (2016), alude que o processo de mediação em conflitos familiares é de interesse do Estado, pois para este, a família é a base da sociedade, merecendo então sua proteção, o que consta no artigo 226 da Constituição (p.76). Desse modo, as autoras 
mencionam que no ano de 2010, foi criado o Centro Judiciário de Solução de Conflitos e Cidadania (CEJUSC), conforme a determinação do Conselho Nacional de Justiça (CNJ), com profissionais abalizados em articular soluções para a incompatibilidade familiar por meio de autocomposição (p. 77), ou seja, que os envolvidos entrem em consenso mútuo de maneira pacífica.

Devido às circunstâncias e entendendo melhor a função da mediação num processo judicial, a análise das mediadoras tem relevante significado para a pesquisa, pois elas representam o primeiro contato legal que os pais são submetidos, antes a da execução de guarda dos filhos o que no possibilita distinguir as razões da guarda compartilhada não acontecer na prática.

Para a coleta de dados, foram feitos contatos prévios com os participantes da pesquisa e então agendado um horário para gravar as entrevistas semiestruturadas, sendo que dois homens foram entrevistados individualmente na mesma instituição de educação infantil, quando foram levar ou buscar as crianças na escola; dois foram entrevistados individualmente em suas próprias residências e as mediadoras foram entrevistadas juntas no ambiente de trabalho, ou seja, no Tribunal de Justiça.

Para preservar a identidade dos participantes, conforme combinado durante a realização das entrevistas, os nomes e as cidades em que os quatro homens e duas mulheres residiam não são declarados, sendo neste estudo identificados por:

Avô 1 - Tinha 51 anos, trabalhava como gerente de um mercado e havia estudado até a sexta série. Morava somente com a neta de 4 anos, dividindo a responsabilidade com a ex esposa, a avó da criança que tinha outra residência.

Avô 2 - Tinha 57 anos de idade, era militar aposentado, cursava licenciatura em Letras, trabalhava como professor de idiomas, no momento da entrevista morava com o neto de 4 anos. Anteriormente o pai da criança morava junto, mas havia se mudado e o avô dividia as responsabilidades do neto com a ex esposa, avó do menino, que tinha outra residência.

Pai 1 - Tinha 33 anos, com ensino médio completo, trabalhava como operador de máquinas de equipamentos, residia com seu filho de 8 anos, desde o nascimento, devido ao falecimento da mãe logo após o parto. Também era pai de uma menina de 2 anos, que morava com a mãe, mas era participativo na criação da criança. A casa em que residia com o filho ficava no mesmo terreno ou quintal em que morava uma irmã, tia da criança.

Pai 2 - Tinha 24 anos, estudou até o segundo ano do ensino médio e exercia a função de analista de controle de qualidade, morou com sua mãe durante um determinado tempo, após a separação conjugal e posteriormente passou a morar com uma irmã. Era responsável pelo filho mais velho, de 3 anos de idade, desde o rompimento com sua ex esposa, quando a criança tinha 2 
anos de idade. Também tinha um filho caçula de 1 ano e 9 meses que passou a morar com ele, quando o bebê tinha 7 meses.

M.1 - Tinha 35 anos, bacharel em Turismo e Direito, tendo também formação de Mediação pelo Tribunal de Justiça reconhecido pelo Conselho Nacional de Justiça, especialização em Processo Civil e em Direito Educacional, atuante na mediação na vara familiar por 1 ano e 9 meses.

M.2 - tinha 25 anos, bacharel em Direito, formação como mediadora e conciliadora pelo Conselho Nacional de Justiça e pós-graduanda em Relações Internacionais Contemporânea, atuava como mediadora no período de 1 ano e 9 meses.

As informações obtidas durante a entrevista semiestruturada por meio de gravações, foram transcritas, analisadas e comparadas a estudos copiosos autores de discutem temáticas correlativas, essas análises serão exibidas a seguir.

\section{RESULTADOS E DISCUSSÕES}

Considerando o fato de que na maioria dos casos em que o assunto é cuidar de criança, principalmente nos seus primeiros anos de vida, as mães são socialmente consideradas as grandes protagonistas e principais responsáveis. No entanto, o interesse do presente estudo é justamente averiguar a exceção desse cenário por priorizar as experiências de homens que cuidam e educam crianças de 0 a 6 anos na família. Desse modo, a fim de se obter conhecimentos sobre a temática, a discussão da pesquisa segue primeiramente com uma análise das experiências dos pais e avós, em que relatam sobre os conflitos, as vivências e opiniões em ter homens cuidando de crianças na atualidade. Em seguida, são apresentados os depoimentos das mediadoras que atuam na vara familiar, como agentes pacificadoras e intermediadoras para chegar a um consenso referente à guarda do menor. Considera-se relevante a opinião das mediadoras, visto que a intenção era pesquisar homens que cuidam de crianças por terem a guarda compartilhada, mas como não foram encontrados sujeitos com esse perfil, as mediadoras têm condições de esclarecer como tem acontecido na prática o cumprimento da referida lei (da guarda compartilhada) em alguns municípios do Estado de Mato Grosso do Sul.

\subsection{EXPERIÊNCIAS E OPINIÕES DE HOMENS TUTORES DOS MENORES}

Ambos os avós estavam à frente dos cuidados dos netos desde o nascimento dos pequenos. Sendo o Avô 1 responsável por uma menina de 4 anos e meio e o Avô 2 com um menino na mesma faixa etária. Quanto a um dos pais, a situação era similar, visto que o Pai 1, foi incumbido 
da guarda do filho recém-nascido, devido a morte da mãe, ocorrida no dia seguinte após o parto. Ele não aceitou o pedido da avó materna de ficar com a guarda do bebê e assumiu a responsabilidade de cuidar e educar da criança que já tinha 8 anos de idade. Com a filha caçula, fruto de um relacionamento não próspero, as circunstâncias eram outras, porque mesmo se fazendo presente e participativo, o Pai 1 não era o único responsável e a menina de 2 anos residia com a mãe. O Pai 2 assumiu a incumbência de cuidar dos filhos após a separação conjugal ocorrida há um ano, primeiramente ele cuidava apenas do mais velho ( 3 anos) e há 7 meses passou a cuidar também da criança menor (1 ano).

Quando indagados sobre a questão da nova estrutura familiar, ou seja, a opinião em relação às famílias monoparentais ou homoafetivas, as respostas do Pai 1 foram positivas, pois segundo ele, o que importa é a formação da criança no que se refere ao caráter e a afetividade envolvida. “Ah, o mais importante mesmo, e independente de sexo, se é masculino ou feminino, é ter o carinho, é você ensinar pra ele a ser um bom cidadão, crescer com uma boa conduta e... crescer. É você preparar ele pra vida, né" (PAI 1). De forma semelhante, o Pai 2 declara: "Ah, é assim, independendo de tá junto ou não, tipo, os dois têm que zelar pelo bem-estar da criança e tal, sempre, tipo, se não ficar junto, mas tem que tá visitando, que nem o meu caso”.

Percebe-se que ambos se preocupam com o bem-estar das crianças, envolvendo afeto, respeito e uma estrutura emocional e não demostram preconceito em relação a família monoparental, que no passado, foi crucificada devido ao fato de a princípio serem compostas por mulheres, portanto, os filhos eram discriminados, conforme relata Santos e Santos (2009, p. 140): “[...] a marginalização ocorreu até a metade deste século, através da denominação atribuída aos filhos desta categoria. Os mesmos eram tidos como ilegítimos perante a sociedade". Quanto a família homoafetiva, da mesma forma, os pais não revelaram pensamentos contrários, já o Avô 2 , manifestou pontos de vista adverso aos dois modelos familiares, quando questionado a contribuição dos homens na educação de crianças pequenas, principalmente no caso de um casal de homens sendo os responsáveis.

A melhor educação para a criança, eu acho seria ter a educação do pai e da mãe, do homem e da mulher. Eu vou ser sincero eu acho um casal homossexual masculino cuidar de uma criança a dificuldade assim é muito grande, por que Deus fez o homem a mulher e aí um completa o outro. O homem teria que ter que ter muito amor pra poder superar todas essas coisas, para fazer tantas coisas. Acredito que um casal homossexual mulher e mulher cuidariam bem de uma criança, bem melhor do que um casal homem, nisso aí eu sou um pouco preconceituoso [...] Na questão de criação eu já tenho minhas dúvidas, eu sou meio preconceituoso, dois homens cuidando de uma criança que não tem sangue... (AVÔ 2). 
Essa ideologia de que um homem não é capacitado para as funções que envolvem os cuidados dos filhos está internalizado na sociedade, ou seja, de acordo com Crepaldi et al. (2006, p. 580):

\begin{abstract}
Parece existir um paradoxo entre as exigências feitas e as possibilidades oferecidas a estes pais. Além disso, em alguns casos em que o pai insiste em tornar-se participante, não raro surge a falta de reconhecimento pelo seu engajamento nesse cuidado, ou seja, não apenas as mães, mas a sociedade como um todo, costuma não valorizá-los.
\end{abstract}

Mas as realidades dos sujeitos entrevistados indicam situações opostas, sendo eles os principais responsáveis pelos filhos, revelaram que até o momento não tiveram dificuldades em exercer esse papel: "Essa é uma responsabilidade que eu tenho, e até hoje, graças a Deus, tá encaminhando bem, meu filho tá com 8 anos e nós somos felizes dessa forma (PAI 2)". Inclusive são bem compreendidos em seus empregos quando se trata de acompanhar os filhos, "[...] pelo fato de trabalhar assim, no serviço, às vezes é complicado, só que eles [patrões] entendem né, por causa que daí eu tenho dois e eles sempre me liberam. Então não acho dificuldade nenhuma” (PAI 2).

Ao serem indagados sobre o preconceito sofrido por eles, pelo fato de ser homem e cuidar dos filhos, ambos os pais relataram não ter padecido de tal situação: "Eu nunca sofri preconceito, é... eu tive muito elogio, eu tive muita parte positiva em relação a isso aí, nunca negativa, todo mundo diz 'Ah, nossa! Você cuida do seu filho? " (PAI 1). Pelo contrário, parece que são considerados socialmente como heróis: "[...] sempre as pessoas quando veem eles comigo, falam assim 'Ah, é seu filho?' Eu falo 'É meu filho tal'. Daí eles falam assim 'Nossa! Parabéns por você ser pai e mãe!' Sempre eu sou elogiado em tudo" (PAI 2).

Entende-se, mediante essas narrativas, que a função realizada por ambos os sexos se destaca quando é exercida por um homem, uma vez que muitas mulheres também desempenham socialmente o papel de pai e mãe e não recebem os mesmos elogios que os homens. De acordo com Louro (1997, p. 19), “[...] os conhecimentos adquiridos pela sociedade, mesmo que realizados por mulheres, não lhes eram atribuídos o mesmo reconhecimento que os homens, os quais eram renomados, enquanto as mulheres tinham seus nomes expostos apenas no rodapé”. Embora o Pai 1 tenha declarado que nunca havia sofrido preconceito devido aos cuidados de seus filhos, no decorrer do diálogo, o mesmo relata que em certo momento, foi tratado de forma diferenciada quando seu filho foi hospitalizado, a criança não foi acomodada no mesmo leito com as demais, pelo fato do acompanhante ser homem, e em sua maioria, nessas circunstâncias, somente as mulheres acompanham os filhos. 
Aí falou 'Traz a mãe'. Eu disse "Não, ele não tem mãe, eu é que vou ficar". Teve uma barreira muito grande, inclusive não queria deixar eu ficar [...] por eu ser um homem. Só que daí eu tinha falado com a doutora, e ela é que me autorizou a ficar. Aí eles me, tipo..., me excluíram num quartinho lá no fundo [...] porque, sempre onde tem um quarto onde tem criança, sempre tem a presença feminina, né. Aí tem esse preconceito né, um monte de mulher aí e um homem no meio, não bate (PAI 1).

Situações como essa evidenciam as representações sociais sobre as relações de gênero, baseadas em constatações empíricas, a respeito de um homem realizar funções consideradas femininas, em um espaço atribuído a mulheres. Nesse sentido, Rabelo (2013, p. 911) salienta que tal atitude provém tanto do homem quanto da mulher: "No entanto, em geral, ambos assumem modelos de comportamento que lhes são socialmente impostos como se fossem naturais, partilhando pressupostos e contribuindo para acentuar a diferença de gênero". Portanto, o cenário referido gera estranhamento, sendo entendido como algo anormal. O mesmo acontece quando um profissional do sexo masculino exerce atividades julgadas como femininas socialmente. $\mathrm{O}$ professor homem, por exemplo, tende a não ser bem visto em seu ofício, quando o assunto se refere à cuidados infantis e assim sua capacidade profissional e sexualidade são colocada em julgamento.

Essa discriminação tem suas bases nos mesmos critérios de gênero que levam alguém a julgar que um homem é homossexual, ou seja, ela se refere às qualidades associadas a cada gênero. Mas nesse caso, o olhar se inverte: ele é homem e por isso não tem as características femininas essenciais para ser um bom professor das séries iniciais do ensino fundamental (RABELO, 2013. p. 916).

Ao serem indagados sobre a necessidade da presença feminina na criação dos filhos, o PAI 1 demostrou certas dúvidas em sua avaliação: "Eu não vejo necessidade, mas se tiver seria interessante". Já o PAI 2 foi bem centrado em sua resposta: "Ah sim, aham, a mãe é necessária, certeza". O Avô 1 segue a mesma linha de pensamento:

Eu sou avô dela e ela tá crescendo. Então ela tem que conviver mais com a vó dela, com a mãe [...] Eu acho que ela tem que conviver cinco, seis anos perto de uma pessoa mulher, para dar banho, para pentear um cabelo, tudo é mais difícil para o homem. É mais difícil cara, é igual um professor ficar cuidando da criança em banheiro né, há uma dificuldade.

Ferreira e Vaisberg (2006, p. 137), fundamentam-se nas ideias do autor psicanalítico Winnicott para explicar esse pensamento a partir da ideologia de que a mãe protagoniza o papel principal na vida das crianças: “[...] a conviçção de que a mãe é tão fundamental à constituição da subjetividade quanto o ar que o bebê respira, principalmente, nos primeiros meses de sua vida". Os pais entrevistados ainda argumentam que as mães têm mais facilidade para se relacionar com as 
meninas: “[...] porque uma menina, ela tem mais facilidade de conversar com a mãe, né. Agora, o pai é um pouco mais restrito né, e a mãe também sabe a necessidade, sabe como é que funciona. Eu acho que nessa parte pode ter alguma barreira" (PAI 1). Também dizem que as mulheres dificilmente confiariam ao pai os cuidados com as filhas: "É porque geralmente a menina já é mais apegada com a mãe. E tipo se fossem duas meninas, acho que ela não deixaria assim eu pegar de mão beijada, assim" (PAI 2).

Os relatos colocam a prova a capacidade de o pai lidar com as funções relacionadas aos filhos, deixando explícito que a preocupação maior é voltada aos cuidados das meninas. Para Bustamante e Trad (2005, p. 1870), "O gênero da criança envolve diferenças importantes nos modos de cuidar. Homens e mulheres consideram que a menina precisa de mais cuidados corporais que o menino, na higiene e na arrumação". Ou seja, as diferenças de gênero se tornam visíveis na sociedade, enfatizando que homem até pode cuidar de criança pequena, desde que se trate de um menino. Isso significa que, de acordo com as representações sociais predominantes na sociedade, as crianças do sexo masculino podem ser cuidadas por homens e mulheres, enquanto que as crianças do sexo feminino devem ser cuidadas somente por mulheres, estando, portanto em desvantagens.

\subsection{PARECER DAS MEDIADORAS EM RELAÇÃO À GUARDA COMPARTILHADA}

Durante a busca por sujeitos que portassem a guarda compartilhada, descobriu-se que na região onde foi realizada a pesquisa, não havia respectivos casos, portanto, fez-se crucial aos estudos, entrevistar mediadoras que embora não tenham o poder decisório (sendo ofício do juiz) sobre o acordo de guarda, lidam diariamente com assuntos familiares destacados na pesquisa. É importante ressaltar que para tal atribuição, não é exclusivamente necessário a graduação em Direito, deve-se ter uma formação superior independentemente do curso e dispor de uma formação específica do Conselho Nacional de Justiça que habilita tal profissional a atuar na área. Desse modo, o objetivo de entrevista-las, se deve ao fato de esclarecer a escassez de casos de guarda compartilhada na região. Ambas as mediadoras, acompanham processos legais referentes ao tema desde 2015, e suas respostas são bem claras quanto a aplicação da guarda compartilhada.

De acordo com Neto e Mafra (2015), “A introdução da guarda compartilhada no ordenamento jurídico positivo brasileiro foi uma grande conquista e também um meio de conferir eficácia ao princípio da igualdade entre homens e mulheres, no tocante à guarda dos filhos menores (p. 391)”. Contudo, esse modelo de guarda não se adequa totalmente a realidade dos envolvidos de acordo 
com os depoimentos das mediadoras. A entrevistada M.2 aponta pontos negativos que impedem o cumprimento da mesma, sendo eles a falta de concordância entre outra legislação, executadas por órgãos competentes ao atendimento das crianças, como escolas e hospitais que possuem um procedimento burocrático que não condiz com a guarda compartilhada.

A gente vê uma certa dificuldade na guarda compartilhada, pelo menos nos casos que são trazidos pra gente, [...] o restante da legislação, ela não tá de acordo com isso, quando por exemplo, um pai sozinho que possui a guarda compartilhada, ele não pode internar o filho, o outro pai tem que estar presente, fazer matrícula da escola. Se uma mãe ou um pai for sozinho fazer a matrícula da escola e essa é guarda compartilhada, não consegue matricular (M.2).

Também a M.1 ressalta que entre as dificuldades encontradas na aplicação da guarda é que o Brasil não possui uma cultura de primeiro mundo, onde se tem uma boa execução da mesma, já que na prática, para que a lei se torne efetiva, imprescindível que os genitores precisam nutrir uma convivência amigável e contatos frequentes, o que dificilmente ocorre após uma separação conjugal.

O povo latino, acho que já vem de sangue, ou ainda não tem a cultura de separar, de, por exemplo, os relacionamentos [...] o que eu percebo na mediação, é que os relacionamentos, eles vêm carregando uma carga emocional muito grande, e é muito difícil das pessoas conseguirem separar a mágoa que veio do relacionamento, do tratamento com a criança e a guarda compartilhada, exige que os dois se responsabilize da mesma maneira e ao mesmo tempo por aquela criança (M.1).

A informação da M.1 vai ao encontro da perspectiva de Alves (2009), por considerar que a relação árdua dos pais após a separação conjugal, impede a aplicação do instituto em questão. "De fato tal priori, apresenta-se extremamente improvável a missão de promover o compartilhamento do exercício do poder familiar entre pessoas que continuam em conflito, sendo o convívio entre elas fonte de incremento desse mesmo conflito (p. 251)". A mediadora explica que em tese, a legislação busca harmonia para manter o poder familiar, onde os pais possuem responsabilidades conjuntas referentes a prole dos filhos, todavia, na prática, isso não transcorre. "No papel fica muito bonito, ninguém fica sobrecarregado, mas na verdade, na prática, se os dois não têm uma comunicação ativa, isso não consegue, só gera mais danos pra criança [...] acabam que as crianças, sendo usada como moeda [...] como desculpa para se agredirem".

Nessa lógica, Velly (2011, p. 10) expõe que “A medida que o ódio avança, também avança a utilização dos filhos como meio de vingança". Destarte, o que fica perceptível é que na teoria, a guarda compartilhada se constitui a melhor escolha para o bem-estar das crianças, no entanto, o mau relacionamento dos pais acarreta em danos maiores para os mesmos. Nesse sentido, a M.1 
defende as mesmas ideias propostas por Fehlauer (2009), de que o relacionamento dos pais é o principal aspecto a ser averiguado antes de se determinar a guarda compartilhada.

Durante o tempo de atuação das mediadoras, ambas expuseram dificuldades em acordar a guarda compartilhada, principalmente pela visão desvirtuada dos pais que a buscam. "Eles têm um conhecimento equivocado da guarda compartilhada, eles acham que a guarda compartilhada é a guarda alternada [...] Eles acham assim, primeiro, eles escutam de uma maneira leviana, que se ele tiver a guarda compartilhada, ele não precisa pagar pensão” (M.2). Nesse sentido, Alves (2009, p. 243), salienta que a "[...] guarda compartilhada não pode jamais ser confundida com a chamada guarda alternada: esta, não recomendável, tendo em vista que tutela apenas os interesses dos pais". Já no caso da pensão, o autor aduz que "[...] a guarda compartilhada não elimina, por exemplo, a clássica pensão alimentícia a ser assumida por um dos genitores” (p. 242). Na realidade, o que se subentende é que os pais procuram a guarda compartilhada a fim de safar de tal obrigação, ou seja, gastos financeiros na manutenção e não realmente por se preocupar com o conforto dos filhos.

Quando os genitores recebem as informações sobre a referida lei, comumente desistem em seguida, de acordo com as mediadoras. Antes que tomem a decisão sobre a guarda, as mediadoras aplicam uma técnica nomeada como "teste de realidade", a qual resulta na renúncia ao acordo de partilha: “[...] nesse teste de realidade, a gente faz perguntas de como é o dia a dia das pessoas, da criança, normalmente nesse rápido teste de realidade que a gente faz, é tanto o pai quanto a mãe, eles já desistem da guarda compartilhada, eles já cedem” (M.2). De certa maneira, as informações evidenciam que os pais não estão prontos para dividir obrigações e cuidados com os filhos, fato esse primordial para a lei da guarda compartilhada, segundo Neto e Mafra (2015).

Outro ponto o qual foi exposto pelas mediadoras, foi sobre o nível de escolaridade dos pais, se interfere na opção pela guarda compartilhada, mas as duas mediadoras disseram que não há diferença. A questão que se sobressai, segundo elas, é que os homens têm se devotado em relação a guarda unilateral, algo recente na sociedade, já que antes o que predominava era que as mães assumiam sozinhas o papel de cuidadora.

Eu percebi que houve um aumento muito grande na procura do homem, procurar a guarda (unilateral) aqui [...] a mulher continua sendo a que mais procura, mas de 2015 pra cá, houve um aumento muito grande nas ações, em que os pais procuram [...] eles têm batalhado mais e se mostrado mais presentes na vida da criança, dos que eu atuei (M.2).

Essa perspectiva vai ao encontro da afirmação de Gontijo (2006 p. 04): “Hoje a realidade é outra, temos muitos pais (homens) que se dedicam a cuidar de seus filhos com carinho, amor e dedicação", percebe-se com essa referência que a sociedade tem se transformado paulatinamente, e que os homens têm tomado posições que anteriormente não foram delegadas a eles. 
Quanto à preferência dos pais entre as guardas, a mulheres demonstram preterir a compartilhada de acordo com as declarações das mediadoras, quando indagadas sobre quem mais rejeitava esse tipo de guarda, a M.2 respondeu: "Eu diria que a mulher, ela tem uma certa rejeição pela guarda compartilhada, pelo sentimento materno mesmo". Mais uma vez aparecem as representações de gênero, de que a mulher por ter o "sentimento materno" deve se responsabilizar pelos cuidados dos filhos e o homem é considerado incapaz de cuidar de criança (BUSTAMANTE; TRAD, 2005).

Dessa maneira, as mediadoras afirmam que apenas casos esporádicos de guarda compartilhada se efetivaram e acreditam que por mais que esse tipo de guarda em sua composição tenha a preocupação de garantir uma vida melhor ao menor, na prática, ainda possui obstáculos diversos. Geralmente esses obstáculos estão ligados às questões de gênero e não tanto pelo fato de os homens se esquivarem de suas obrigações de pai, mas sim devido ao relacionamento dos genitores que acabam impedem de oficializar a guarda compartilhada. Portanto, a guarda mais eficaz na opinião das mediadoras é a unilateral, sendo acordada para qualquer um dos genitores, independente de gênero, sendo priorizado àqueles genitores que são totalmente capazes de tal função.

\section{CONSIDERAÇÕES FINAIS}

Com base nas informações levantadas durante a pesquisa, para analisar questões relacionadas aos homens cuidando criança pequena em âmbito familiar, observou-se vários aspectos legais que possibilitam o sexo masculino serem participativos na vida de uma criança, sendo eles; a família monoparental e homoafetiva o direito à licença paternidade, a guarda unilateral e a guarda compartilhada.

Os dados coletados a partir dos relatos dos homens, que de alguma forma, se tornaram os responsáveis por criança na família, evidenciam que foram poucas as dificuldades que enfrentaram, pelo contrário, são considerados como heróis, em grande maioria, são exaltados por exercerem a função de ficar com as crianças, já que socialmente, essa obrigação é conferida às mulheres. Para eles, os cuidados dos filhos não são onerosos, e que executam com muito prazer. Desse modo, percebe-se que no âmbito familiar, o fato do homem cuidar e educar as crianças não gera estranhamentos, no entanto, se os envolvidos não possuem laços sanguíneos, as opiniões mudam radicalmente, tal como o episódio em que o Pai 1 não pôde acompanhar seu filho no momento que precisou ser hospitalizado, tendo que ser acomodado em um quarto isolado, pois sua presença 
poderia constranger as mães que acompanhavam as demais crianças, ou então o fato de um casal homossexual terem a custódia de crianças, como ficou bem claro na declaração do Avô 2 .

A esfera familiar também contradiz ao escolar, ou seja, quando se trata de professores do sexo masculino lidar com cuidados infantis, costuma-se ser adversas às opiniões, os mesmos sofrem fortemente discriminações referente às questões de gênero durante sua trajetória, acreditando-se que não possuem habilidade para exercer tal atividade.

Quanto a guarda compartilhada, sendo judicialmente vista como a lei de guarda que mais atende as necessidades dos filhos, em que os direitos e deveres dos pais são atribuídos de maneira igualitária, as declarações das mediadoras revelam que o motivo da mesma não se plicar na prática, se deve ao fato de esse tipo de guarda exigir dos genitores uma relação pacífica, o que na realidade, dificilmente acontece. Por tanto, no decorrer da pesquisa, percebeu-se que a sociedade está em processo de constantes mudanças, e que os homens atualmente têm se tornado participativo na vida dos filhos, isso no âmbito familiar, pois no contexto escolar, quando o assunto é homem cuidando de criança pequena, as perspectivas são negativas.

\section{REFERÊNCIAS}

ALVES, L.B.M. A guarda compartilhada e a Lei no 11.698/08. In: Biblioteca Virtual do

Ministério Público do Estado de Minas Gerais. n.13. p.235-258, jul./dez. 2009. Disponível em: https://aplicacao.mpmg.mp.br/xmlui/handle/123456789/81. Acesso em: 29 jun. 2020.

BITENCOURT, S. M. A contribuição de teóricas feministas para os estudos de gênero. Revista Ártemis, vol. XVI n 1; p. 178-185, ago./dez., 2013.

BUSTAMANTE, V; TRAD, L. A. B. Participação paterna no cuidado de crianças pequenas: um estudo etnográfico com as famílias de camadas populares. In: Cadernos de Saúde Pública, Rio de Janeiro. v.21. n. 6. nov./dez. 2005. Disponível em:

http://www.scielo.br/scielo.php?script=sci_arttext\&pid=S0102-311X2005000600036. Acesso em: 17 nov. 2020.

BRASIL. Congresso Nacional. Ampliação da licença paternidade para 20 dias. Lei n¹3.247/16. Diário Oficial da União, Brasília, DF, 08 de mar. 2016.

BRASIL. Congresso Nacional. Altera os Arts. 1.583, 1.584, 1.585 e 1.634 do Código Civil e Estabelece o significado da expressão "guarda compartilhada" e dispõe sobre sua aplicação. Lei n¹3.058/14. Diário Oficial da União, Brasília, DF, 22 de dez. 2014.

BRASIL. Constituição Da República Federativa Do Brasil De 1988. Disponível em: https://www.planalto.gov.br/ccivil_03/constituicao/constituicao.htm. Acesso em: 21 out. 2020. 
CORREIA, S. V. A articulação família trabalho em famílias monoparentais masculinas. In.: Wall, K; Aboim, S; Cunha, V. (Coord.). A vida familiar no masculino: Negociando velhas e novas masculinidades. Lisboa. PT. Editorial do Ministério da Educação. 2010.

CREPALDI, M. A. et al. A participação do pai nos cuidados da criança, segundo a concepção de mães. In: Psicologia em Estudo. Curitiba. Paraná, v. 11, n. 3, p. 579-587, set/dez. 2006. Disponível em: http://www.scielo.br/pdf/pe/v11n3/v11n3Avôi 13.pdf Acesso em: 09 abr. 2020.

DIAS, M. B. Manual de direito das famílias. ed. 5. São Paulo. SP. Revista dos Tribunais. 2009.

DUARTE, R. Entrevistas em pesquisas qualitativas. In: Educar. Curitiba, PR, n. 24, p. 213-225. 2004. Disponível em: www.scielo.br/pdf/er/n24/n24Avôi 11.pdf. Acesso em 12 fev. 2020.

FARIA, A. H.; GONÇALVES, J. P. Educação Escolar e Relações de Gênero Segundo a Perspectiva de Homens Professores. Hispanista, v. XVII, n, 67, out./dez. 2016.

FEHLAUER, L. $O$ instituto da guarda compartilhada no atual direito de família brasileiro. SC. 2009. Universidade do Vale do Itajaí - INIVALI. 2009.

FERREIRA, M.C; VAISBERG, T. M. J. A. O pai suficiente bom: algumas considerações sobre o cuidado na psicanálise winncottiana. Advances in Healtb Psychology. v. 14, n.2, p. 136-a42, jul/dec. 2006. Disponível em: https://www.metodista.br/revistas/revistasims/index.php/MUD/article/viewFile/644/644. Acesso em: 09 abr. 2020.

GODOY, A. S. Introdução à pesquisa qualitativa e suas possibilidades. RAE Artigos. São Paulo. v.35. n. 2. p. 57-63. mar/abr. 1995. Disponível em:

http://www.scielo.br/pdf/rae/v35n2/a08v35n2.pdf . Acesso em: 19 jan. 2020.

GONÇALVES, J. P.; DIAS, É. F. M. D.; SOUZA, V. C. S. Eles são instáveis, agressivos e desnaturados ou têm autoridade, bom senso e firmeza? Presença de homens no magistério e representações sociais. Polêm!ca, v. 17, n.4, p. 44-65, out./dez. 2017.

GONÇALVES, J. P; FARIA, A. H. Olhares de professores homens de Educação Infantil: conquistas e preconceitos. Perspectiva, Florianópolis, v. 34, n. 3, p. 988-1014, set./dez. 2016.

GONÇALVES, J. P.; FERREIRA, V. C. M.; CAPRISTO, Z. R. N. Professores homens desempenham as mesmas funções que as professoras na educação infantil? Olhares dos gestores escolares. Educação em Foco, Belo Horizonte, v. 21, n. 34, p. 136-154. 2018.

GONÇALVES, J. P; OLIVEIRA, L. A. Representações Sociais Relacionadas aos Professores Homens do Ensino Fundamental e as Inevitáveis Associações às Professoras. Acta Scientiarum. Education. Maringá, PR, v. 38, n. 4, 2016.

GONÇALVES, J. P; OLIVEIRA, E. L. Comunidade escolar de Mato Grosso do Sul: refetindo sobre o trabalho de docentes do gênero masculino. Educação, Porto Alegre, v. 40, n. 2, p. 275 258, mai./ago. 2017.

GONÇALVES, J. P.; SOUZA, V. C. S; REIS, M. G. F. A. Gestoras municipais de educação infantil: (des) confiança no trabalho realizado por homens educadores. Interaccoes, Portugal PT, v. 13, p. 172-191, 2017. 
GONTIJO, J. Guarda, poder familiar- bens dos filhos. 2009. In: Juliana e Fernando Gntijo: Advocacia e consultoria das famílias e sucessões. Disponível em: http://www.gontijofamilia.adv.br/material-juridico/direito-das-familias/ Acesso 29 jun de 2018.

JODELET, D. Representações sociais: um domínio em expansão. In: JODELET, D. (Org.), As representações sociais. Trad. Lilian Ulup. Rio de Janeiro: Ed.UERJ, 2001.

LOURO. G. L. Gênero, sexualidade e educação: Uma perspectiva pós-estruturalista. Petrópolis, RJ: Vozes, 1997.

NETO, E, A, M; MAFRA, T, C, M. Guarda compartilhada: entre o superior interesse da criança e as responsabilidades parentais. In: CONPEDI: Conselho Nacional de Pesquisa e PósGraduação em Direito. XXIV Congresso nacional do CONPEDI - UFMG/FUMEC/DOM Helder Câmara. Direito de família e sucessões. Florianópolis. 2015.p. 382-398. Disponível em: http://www.conpedi.org.br/publicacoes/66fsl345/rlmau22a Acesso em: 28 jun. 2018.

RABELO, A. O. Professores discriminados: um estudo sobre os docentes do sexo masculino nas séries do ensino fundamental. Educação e Pesquisa. São Paulo, SP, v. 39, n. 4, p. 907-925, out/dez. 2013.

RAMOS, J. Estudo sobre os professores homens da educação infantil e as relações de gênero na rede municipal de Belo Horizonte - MG. 2011, 139f. Tese (Mestrado em Educação) - Pontifícia Universidade Católica de Minas Gerais. PUC/ MG. Minas Gerais, 2011.

SANTOS, J. B; SANTOS, M. S. C. Família monoparental brasileira. In: Revista Jurídica, Brasília. v. 10, n. 92, p. 01-30, out/2008 jan/2009. Disponível https://revistajuridica.presidencia.gov.br/index.php/saj/article/view/209/198 Acesso em: 06 abr. 2020.

SCOTT, J. Gênero: uma categoria útil de análise histórica. In: Educação e realidade, Porto Alegre, v. 2, n. 20, jul./dez. 1998.

SUTTER, C; MALUSCHKE, J. S. N. B. Pais que cuidam dos filhos: a vivência masculina na paternidade participativa. v. 39. n. 1. p. 74-82. Jan /mar. 2008.

TAKASSI, G. A. R; BERTONCINI, C. Pacificação Familiar no Judiciário: A mediação como forma de Manutenção do Vínculo de Afetividade. In: XXV Congresso do CONPEDI-

Curitiba. Direito de Família e sucessões II. 2016. Disponível em:

www.conpedi.org.br/publicacoes/02q8agmu/8v3pu3uq/Mv20a6lh6AH6F916.pdf. Acesso em: 22 abr. 2020.

VIANNA, C.; FINCO, D. Meninas e meninos na Educação Infantil: uma questão de gênero e poder. Cad. Pagu, Campinas, n. 33, p. 265-283, dez. 2009.

TJMS, Tribunal de Justiça do Estado de Mato Grosso do Sul. Manual de Mediação Judicial. p. 247. (Org). André Gomma de Azevedo. Conselho Nacional de justiça. Campo Grande, MS. 2015.

VELLY, A, M, F. Guarda compartilhada: uma nova realidade para pais e filhos. 2011. Disponível em: 
http://www.ibdfam.org.br/ img/artigos/Artigo\%20Guarda\%20Compartilhada\%2029 062011. pdf. Acesso em: 25 jun. de 2020. 